Brit. Heart Y., 1966, 28, 845.

\title{
Percutaneous Intravenous Insertion of an Ordinary Double-lumen Catheter
}

\author{
BENGT JONSSON \\ From the Laboratory of Clinical Physiology, Thoracic Clinics, Karolinska Sjukhuset, Stockholm 60, Sweden
}

Dissection and ligation of veins should be avoided when catheters are inserted for diagnostic procedures or for intravenous therapy. Seldinger's catheter replacement technique (1953) has been widely used for both arterial and venous percuttaneous catheterization. An ordinary Cournand catheter cannot, however, be inserted by this technique as its end is blunt. The use of a doublelumen catheter has great advantages for catheterization of the right side of the heart. By observing the pressure on a recorder or an oscilloscope, the side hole of the catheter can be moved between the right ventricle and the pulmonary artery and thus the hole at the tip moves between the pulmonary artery and the wedged position without using fluorscopy. This is of great value when patients are studied during exercise, and double-lumen catheters are used routinely in this department. A technique for percutaneous insertion of this type of catheter has, therefore, been developed.

Received February 18, 1966.

\section{Technique}

After puncture of the vein (Fig. 1a and Fig. 2A), a nylon cord, diameter $0.7 \mathrm{~mm}$., is inserted through the needle which is thereafter withdrawn. The hole in the skin around the nylon cord is enlarged by a small pair of scissors to a width that will allow the double-lumen catheter to pass (Fig. 2B). Three teflon catheters with outer diameters of $1.5,2.3$, and $2.8 \mathrm{~mm}$. (b, c, and d, in Fig. 1), one threaded over the other and the thinnest over the nylon cord, are inserted into the vein using the nylon cord as a guide (Fig. 2C). The tip of each catheter is well adapted, so that no sharp edges exist as hindrance for passage into the vein. This adaptation is easily done by stretching the catheter at a temperature of about $300^{\circ} \mathrm{C}$. The widest catheter is very thin and 5-8 cm. long. Its proximal end has been widened by a hot pricker and the collar will prevent this end of the catheter from passing the hole in the skin. Furthermore the catheter has a longitudinal slit from the collar end to about half its length. The nylon cord and the two thinner teflon catheters are withdrawn and thus only the shortest and widest teflon catheter remains in the vein. The tip of the double-lumen catheter is inserted through this catheter

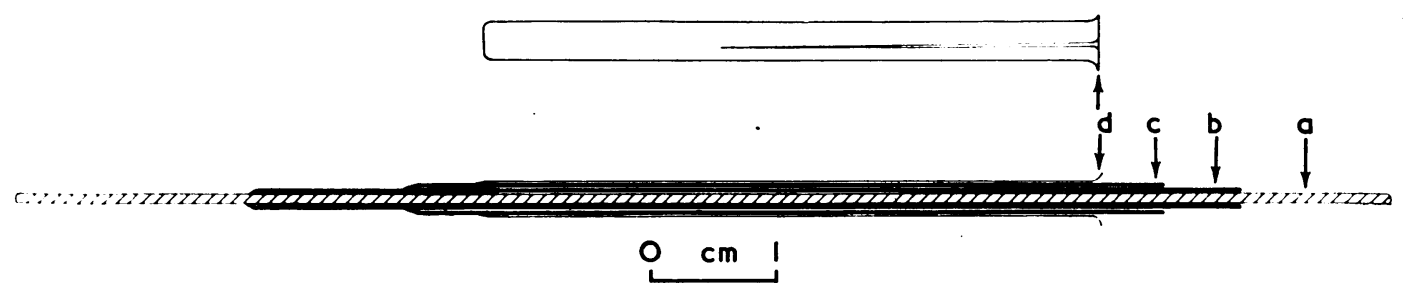

FIG. 1.-Nylon cord with three teflon catheters, threaded one over the other. The widest catheter has a slit. 


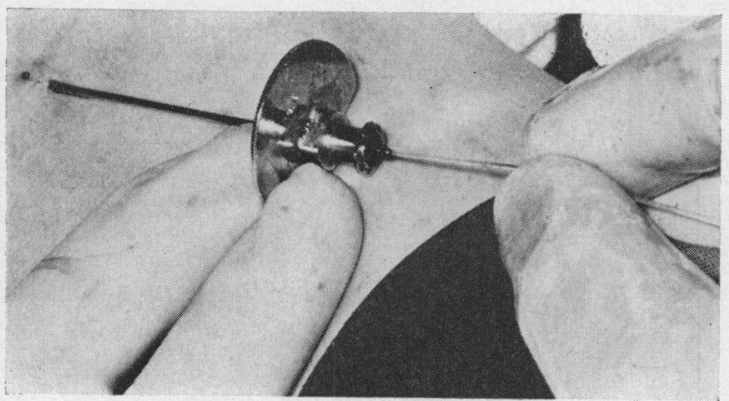

A

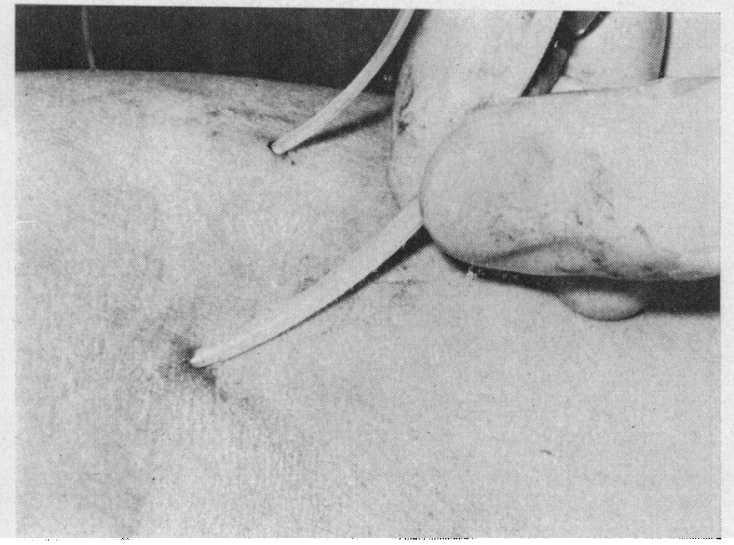

C

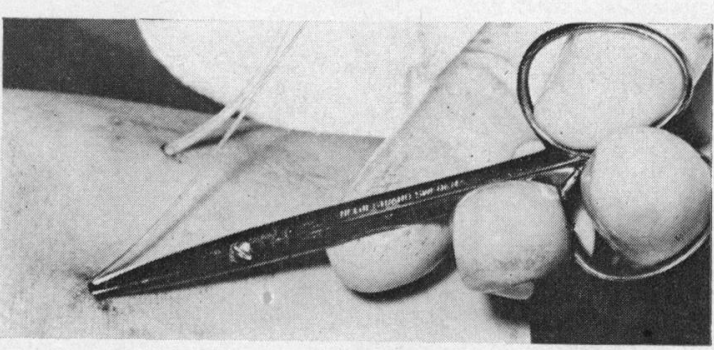

B

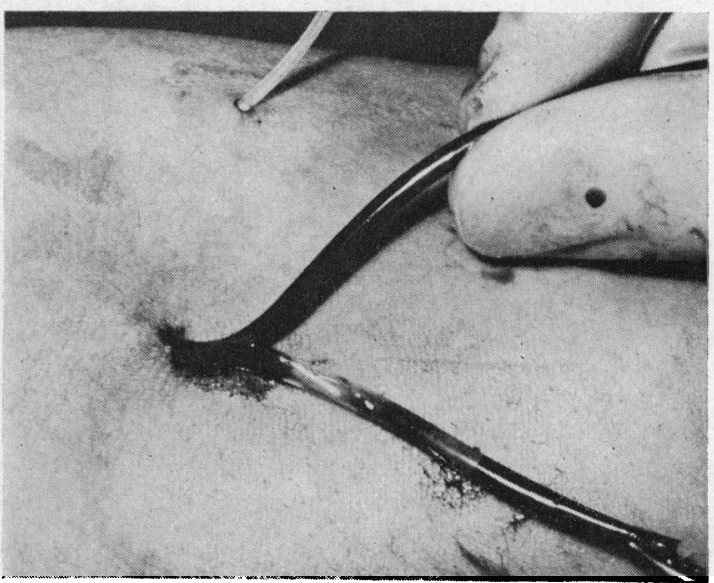

D

Fig. 2.-(A-D) Different steps for intravenous insertion of a double lumen catheter (see text). A teflon catheter is inserted into the brachial artery.

and it can be advanced as far as the side hole. The teflon catheter is then withdrawn, and when the thicker part of the double lumen catheter (proximal to the side hole) is forced into the teflon catheter the slit is extended to the tip (Fig. 2D); then the thicker part of the doublelumen catheter can be advanced into the vein.

This technique has been used in over 50 patients.
Thrombophlebitis has not been seen and the veins have functioned normally.

\section{REFERENCE}

Seldinger, S. I. (1953). Catheter replacement of the needle in percutaneous arteriography. A new technique. Acta radiol. (Stockh.), 39, 368. 